\title{
O ALAZÔN, O OUTRO E O AMIGO DO OUTRO: TEATRO DA DESCONFIANÇA NA TRIBUNA GREGA
}

\author{
Milton L. TORRES* \\ Centro Universitário Adventista de São Paulo
}

Resumo. O alazôn aparece com frequência nas comédias de Aristófanes como uma figura de bloqueio que, por meio de seu maior estatuto social, rigidez, vanglória e impostura, tenta impedir a concretização da utopia cômica. O termo também é empregado, na antiguidade grega, para o cavalo de raça (Pólux, Onomástico 1.195), devido à forma imponente com que este sustenta a crina. Além da comédia, a retórica grega também faz uso abundante do termo, geralmente aplicado a um adversário. Uma vez que o desempenho do orador é comparado à disposição do cavalo no hipódromo (Ésquines, Contra Timarco 1.176) e que a algazarra do tribunal ateniense é comparável à do teatro (Platão, República 492b), sugere-se que o topos da alazoneia serve para estigmatizar um personagem (no teatro) ou um orador (na tribuna) como aproveitador, inimigo do bem comum e representante de interesses alheios aos da pólis. Nesse processo, é possível que seu emprego na comédia e na oratória reforce mutuamente o estigma, promovendo uma desconfiança generalizada no orador/alazôn e nas pessoas com ele relacionadas.

Palavras-chave. Alazôn; comédia antiga; retórica grega; oratória.

D.O.I. 10.11606/issn.2358-3150.v18i2p74-87

A ALAZONEIA (OU "IMPOSTURA") TEM PRESENÇA GARANTIDA NA LONGA HIStória do teatro e da poesia ocidental, sendo identificada, por exemplo, na comédia nova, na comédia latina, na commedia erudita italiana (Boughner 1943, 42-83), em Philip Sidney (Hager 1991, 167-75), em William Shakespeare (Frye 1953, 271-7; Bosch 2000-2001, 205-17), em Jean Molière e Carlo Goldoni (Brunoro 1983), em Bernard Shaw (Speckhard 1958; Casper 1971) e na cinematografia moderna (Hague 1984). Entretanto, em nenhum lugar alcançou tanta importância quanto na comédia antiga.

Aristófanes escreveu cerca de quarenta comédias em quarenta anos de carreira. Dessas comédias, onze sobrevivem espaçadas em 37 anos, das

\footnotetext{
Doutor em Arqueologia Clássica pela University of Texas System (2008) e Doutor em Letras Clássicas pela Universidade de São Paulo (2014), com pós-doutorado em Estudos Literários pela Universidade Federal de Minas Gerais (2009).

“* Artigo recebido em 25.set.2015 e aceito para publicação em 14.dez.2015.
} 
quais cinco se concentram na década de 420 (Storey 1998). Em suas comédias supérstites foram catalogadas mais de quarenta cenas em que ocorre uma participação importante de alazones (Mcleish 1980, 75). Minha proposta aqui é que a alazoneia faça parte do coração das peças de Aristófanes, o que concordaria com o argumento de Cornford (1961 [1914], 183-4; 209-11) de que ela é a contraparte cômica da hybris da tragédia. ${ }^{1}$ Falando da comédia antiga, pode-se afirmar, com base nesta proposta, que a ação cômica depende da disputa (agôn) travada entre um herói passional e irônico, geralmente um eirôn, e o alazôn, a figura cheia de impostura que teima em the atravessar o caminho.

Historicamente, tanto o eirôn quanto o alazôn pertencem a uma categoria dramática de tipo bem estabelecido. Assim, o Tractatus coislinianus (Lane 1922, 262-5) considerou o eirôn, o alazôn e o bômolochos, geralmente um coadjuvante do herói ou um juiz do agôn (Gelzer 1960, 124-5; Féral 2009, 17-18), como "personagens típicos" (êthika prosôpa, em grego). ${ }^{2}$ De fato, a definição filosófica que Aristóteles dá ao alazôn, em sua Ética a Nicômaco 1108a 23 (Bywater 1894), o contrapõe principalmente ao eirôn:

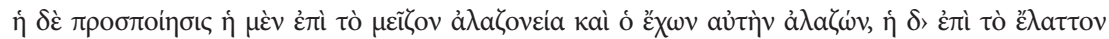

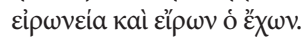

o fingimento para mais é a impostura (alazoneia) e o que o pratica é o impostor (alazôn); o fingimento para menos é a ironia (eirôneia) e o que o pratica é o irônico (eirôn).

O "personagem típico" consistiria, na visão aristotélica, de um estereótipo detentor de certos atributos e atitudes.

A plateia ri do alazôn porque se sente superior a ele, mas, em contraste, ri com o herói porque partilha do conhecimento que este tem da situação. De fato, uma das principais características do alazôn é seu comportamento rígido ("tensão"), produto de seu completo desconhecimento de

\footnotetext{
${ }^{1}$ Aliás, os escoliastas antigos já haviam percebido a relação entre hybris e alazoneia. De fato, é comum que os escoliastas de Ésquilo glosem, por exemplo, o termo hybris como alazoneia kai asebeia, e o termo hybristês como alazôn, o que ocorre, por exemplo, em relação aos versos 821-822 de Os persas (Smith 1976; 1982). Com isso, não se quer dizer, porém, que a comédia seja o polo oposto da tragédia, conforme já ressaltou Silk (2000). Além disso, há estudiosos que preferem ver no alazôn a contraparte cômica do apragmôn trágico, uma figura inerte e desinteressada (Carlevale 1999, 121).

${ }^{2}$ A visão de Aristóteles influenciaria outros autores antigos como, por exemplo, Rutílio Lupo (De figuris sententiarum 2.7), Quintiliano (Institutio oratoria 5.10.19 e 11.3.74) e Hermógenes de Tarso (Peri tôn staseôn 134.4-5). Os personagens típicos são, de fato, recorrentes em vários períodos e gêneros narrativos da literatura universal. No drama elisabetano, por exemplo, encontramos o soldado bravateiro, a heroína disfarçada de rapaz, o camponês crédulo e o vilão maquiavélico. De acordo com Holman e Harmon $(1986,482)$, uma característica da arte moderna é sua tendência de pegar personagens típicos do passado, deslocá-los da periferia para o centro da atenção, e tanto revelar quanto explorar novas complexidades.
} 
si mesmo (Bergson 1978 [1924]). Conforme afirma De Pracontal (2004, 20), “a maioria dos impostores, sinceros ou não, protege-se por detrás de uma muralha de convicções contra a qual os melhores argumentos vão se despedaçar. Os ataques de seus adversários nada mais fazem do que reforçar suas certezas". Assim, Lâmaco (Acarnenses) e o escravo paflagão (Cavaleiros) constituem modelos do alazôn de Aristófanes.

Em contrapartida, o eirôn, o herói das comédias de Aristófanes, apresenta um comportamento flexível ("elasticidade") que demonstra sua genialidade e adaptabilidade (Brunoro 1983, 1-3), como acontece, por exemplo, com Diceópole (Acarnenses) e Agorácrito (Cavaleiros). Além disso, mesmo no final da peça, o alazôn não demonstra ter alcançado qualquer tipo de conhecimento sobre si mesmo, mantendo-se iludido, sem jamais se converter à razão e à ordem que a nova sociedade representa (Wallace apud Hague 1984, 120). Assim, por exemplo, temos, no final de Cavaleiros, o lamento do escravo paflagão de que o oráculo se cumpriu:

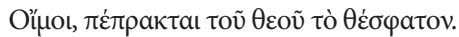

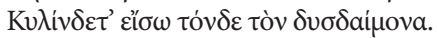

Ai de mim! cumpriu-se o oráculo do deus...

Empurrem para dentro este pobre infeliz!

(Cavaleiros 1248-9)

Por outro lado, a alazoneia é mais do que apenas uma característica de sua personalidade. Ela constitui uma estratégia bem montada pelo poeta para reforçar a fantasia que cria. Nesse sentido, o que Hutcheon (2000, 16) fala da ironia, pode ser dito também da alazoneia: não se trata de um tropos, mas de um topos político com implicações comunicativas e de natureza transideológica (Hoffmann 2008, 14-31). A alazoneia está presente, na obra de Aristófanes, em muitas dimensões, e é especialmente corporificada por alguns personagens que, por essa razão, podem ser chamados de alazones, bem como em alguns desenvolvimentos das peças, as cenas com alazones. Tradicionalmente descritos como "figuras de bloqueio" (blocking characters), pela capacidade que derivam de seu poder ou prestígio social e que é capaz de impedir que a utopia cômica se concretize (Frye 1957, 169), ${ }^{3}$ os alazones se apresentam como criaturas obcecadas, governadas por sua paixão pelo dinheiro, ambição e autoridade, cegas às necessidades alheias, sempre dispostas a reagir de modo mecânico e irracional (Bergson, 1978 [1924]; Brunoro

\footnotetext{
${ }^{3}$ A arte de Aristófanes é feita de "improvisos sucessivos, de uma progressão delirante da ação. E essa poesia, ferozmente absurda, abre uma brecha, uma fenda na ordem, no ritual sagrado e citadino. Uma falha que deixa entrever outro gênero de vida, uma felicidade prometida aos homens, apesar do peso das obrigações, dos hábitos, dos procedimentos" (Duvignaud 1999, 79).
} 
1983, 2); tornam-se o objeto de algum tipo de reconciliação, no término da peça, para garantir o final feliz, mas sem se converter, de fato, à sociedade criada pela utopia cômica e que a plateia contempla como sendo a ideal (Frye 1957, 164). Em geral, predicam sua capacidade de afetar o eirôn e de impedir a utopia cômica em um estatuto social privilegiado. No entanto, quando o autor reverte os valores por eles abraçados, colocando-os no estrato mais baixo da sociedade idealizada pelo eirôn e seus simpatizantes, os alazones conseguem ainda derivar sua capacidade bloqueadora de sua fidelidade à obstinada concepção de que o dinheiro está acima de todas as coisas (Renan 1983, 247).

\section{O CARÁTER HÍPICO DO ALAZÔN}

Ribbeck (1882, p. 1) declara que, inicialmente, o caráter do alazôn era tomado favoravelmente pelos gregos. Para isso, invoca a autoridade do Onomasticon 1.195 (Bethe 1900), de Pólux, erudito do século II A.D., que coloca o termo entre os predicados favoráveis geralmente atribuídos ao cavalo de raça. Com isso, entretanto, Ribbeck (1882) não propõe uma conexão etimológica entre alazôn e "alazão" e tampouco faz referência à cor do animal. ${ }^{4}$ A palavra não aparece, de fato, nem na Ilíada nem na Odisseia. Apesar disso, pode-se dizer que há um alazôn arquetípico na epopeia. ${ }^{5}$ Ribbeck (1882) percebeu esse fato muito bem quando conectou a palavra aos símiles homéricos que apresentam os guerreiros troianos como cavalos. É o que evoca, por exemplo, o símile que descreve o aparecimento de Páris no campo de batalha, no canto vi da Ilíada (6.506-14):

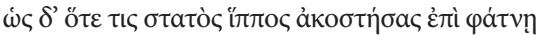

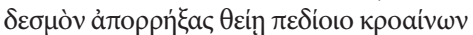

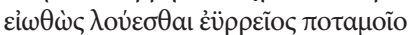

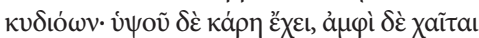

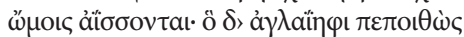

\footnotetext{
${ }^{4}$ Carvalho da Silva (2009) afirma que, no português medieval, o vocábulo "alazão" assumia a forma alaxam, mas não vê relação entre alazôn e "alazão". A palavra portuguesa pode-se associar ao árabe al-hiçân, "cavalo".

${ }^{5}$ A palavra arquétipo não é, aqui, tomada no mesmo sentido proposto por Michele (1999, 8-9), quando se refere provavelmente a um conceito mais próximo à definição de Northrop Frye (apud Holman et Harmon 1986, 36), segundo a qual um arquétipo é "um símbolo, geralmente uma imagem, que recorre com frequência suficiente na literatura para ser reconhecido como parte da experiência literária, como um todo, de uma pessoa". "Arquétipo", aqui, tem o sentido muito menos técnico de padrão inicial a partir do qual a alazoneia se desenvolve. Neste sentido, o termo é um sinônimo aproximado de "protótipo".
} 


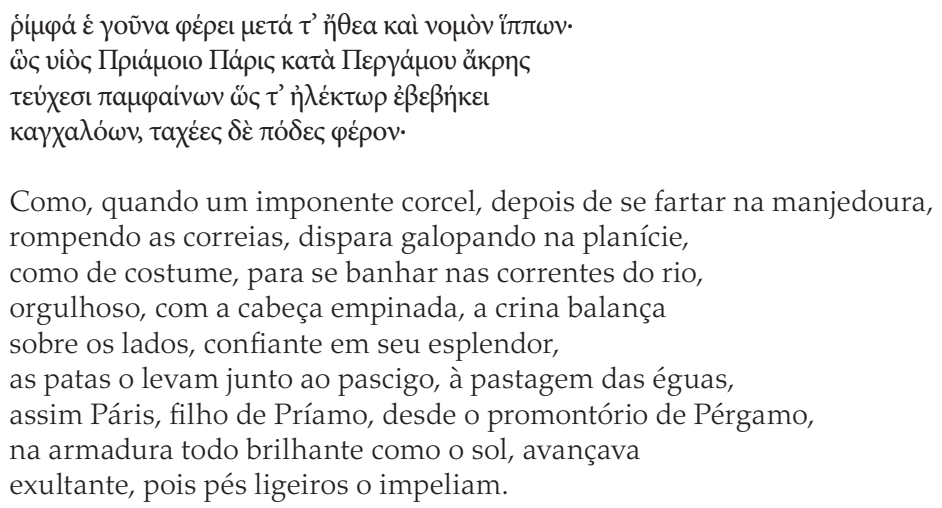

De acordo com o escoliasta da Ilíada (Erbse 1974), a principal razão para a comparação se deve à postura imponente da cabeça:

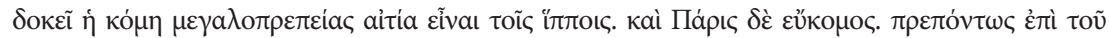

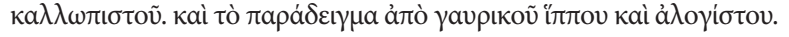

A crina parece ser a causa da magnificência dos cavalos, e Páris tinha uma bela cabeleira, como convinha a quem se adorna com cuidado. A comparação é feita com o cavalo orgulhoso e irracional.

Estabelece-se, portanto, uma conexão entre a cabeleira do herói e a crina do cavalo de raça. $O$ fato de a crina motivar a sensação de orgulho por parte do corcel pode ser confirmado a partir de outro símile, mais adiante no poema (Ilíada 15.263-70):

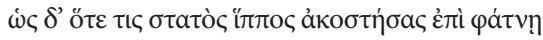

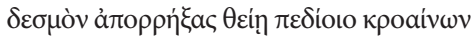

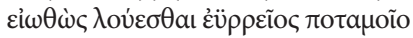

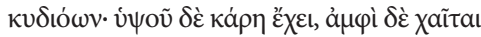

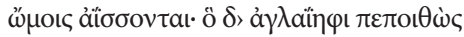

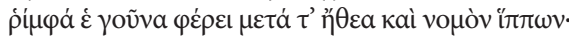

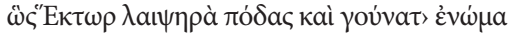

ỏ

Como, quando um imponente corcel, depois de se fartar na manjedoura, rompendo as correias, dispara galopando na planície,

como de costume, para se banhar nas correntes do rio,

orgulhoso, com a cabeça empinada, a crina balança

sobre os lados, confiante em seu esplendor,

as patas o levam junto ao pascigo, à pastagem das éguas,

Assim Héctor movia os pés e os joelhos velozes,

Açodando os cavalos, pois ouvira a voz do deus. 
Ao comentar a provocação de Heitor para que um campeão aqueu o enfrentasse (Ilíada 7.90), o escoliasta da Ilíada (Erbse 1975) afirma que Heitor "é sempre caracterizado" (charaktêrizetai) por Homero como "amante das honras" (philotimos), "jactancioso" (alazôn) e "barbárico" (barbaroêthês). Mais adiante (8.523), o escoliasta reclama que Heitor fala "como tirano" (tyrannikôs), pois não condiz ao príncipe que "fique se exaltando com jactância" (epêrmenos têi alazoneiai). Depois, o escoliasta afirma que "Heitor, por ser arruaceiro (thorybôdês) e jactancioso (alazôn), insensatamente faz convocações de todos os guerreiros" (Ilíada 10.300). Na gesta de Agamenão (canto 11 da Ilíada), o escoliasta aponta para a forma "barbaramente jactanciosa" (barbarikôs alazoneuomenos) com que Heitor se diz protegido por Zeus (11.288-9). No canto 12, o escoliasta diz que Heitor "se vangloria (alazoneuetai) barbaramente junto aos navios gregos" (12.441 $)^{6}$; logo depois, diz que Heitor se jactancia de ser filho de Zeus (13.54). Na Patrocleia, o escoliasta chega a conclamar o leitor a que contemple a impetuosidade (to emplêkton) do bárbaro Heitor (16.833-44). Segundo ele, ainda que reprovasse a "jactância" (alazoneia) de Pátroclo, Heitor mesmo incorre (empiptei) em erro semelhante, pois não considera a vitória como oriunda dos deuses, mas de sua própria força (tês autou dynameôs). Na gesta de Menelau, o escoliasta lamenta que Heitor "se gabe" (alazoneuetai) de ter arrancado as armas de Aquiles do cadáver de Pátroclo (17.187), e menciona que, quando Homero introduz "o próprio Zeus repreendendo a jactância de Heitor" (autos ho Zeus katamemphonos tou Hektoros tên alazoneian), ele está ensinando que cada um tem que "se preocupar com o que é da sua conta" (kath'auton phronein) e não ficar encantado com coisas que ultrapassam sua própria natureza (17.198-208). ${ }^{7}$ Quando, pouco depois disso, em 18.246-83, Polidamante Pantoide propõe que os troianos voltem momentaneamente para dentro da cidade, o vidente acaba repreendido severamente por Heitor, num discurso em que o escoliasta interpreta que Heitor falou "bárbara e jactanciosamente" (barbarikôs kai alazonikôs). Além disso, ao se referir provavelmente aos bravos a quem comandava, Heitor os chama de Hektoros ôkees hippoi possin orôrechatai polemizein, "corcéis velozes de Heitor, galopando para se lançar à guerra" (16.833-4). ${ }^{8}$ A alazoneia de Heitor reforça, portanto, o estereótipo do guerreiro troiano como cavalo de raça.

\footnotetext{
${ }^{6}$ O escoliasta do Códice de Genebra (Nicole 1891) repete essa mesma observação.

${ }^{7} \mathrm{Na}$ mesma passagem, o escoliasta afirma que é "consistente com a jactância de Heitor" (akolouthon têi tou Hektoros alazoneiai) passar primeiramente ao redor a fim de mostrar para cada um "o espólio das armas" (tên ktêsin tôn hoplôn) e, assim, "se tornar visível" (phanênai) para Aquiles (Ilíada 17.215).

${ }^{8}$ É difícil, no entanto, garantir que Heitor esteja, de fato, se referindo a seus comandados, uma vez que a palavra hippoi, em Homero, tem geralmente o sentido de "carruagens" (Willcock 1978, 197). Pode ser, portanto, que seu emprego aqui seja literal e não metafórico.
} 
É possível que, assim como no caso de Heitor, as descrições de Páris tenham, em si mesmas, elementos de sarcasmo (Suter 1993, 1-18). Afinal de contas, ambos representam o inimigo troiano, sendo, por isso, passíveis de caracterização negativa.

\section{O ALAZÔN E O OUTRO}

A oratória da Grécia clássica também viu o alazôn com desfavor e assim o apresentou diante do público de Atenas. Isócrates, por exemplo, em seu discurso Contra os sofistas 13.1 (Mathieu et Brémond 1929), viu os oradores alazones como a principal razão por que, segundo ele, a filosofia estava caindo em descrédito entre os gregos. Sua crítica se dirigia principalmente aos professores de oratória que se propunham, por módicos honorários, a transformar o cidadão comum em mestre dos discursos. Segundo ele (13.9-10), os que se candidatavam a ensinar a arte da oratória deveriam se conscientizar de que a oratória depende mais de técnicas bem treinadas e habilidades naturais do que de sua capacidade de impostura/vanglória (alazoneia). Segundo Isócrates (Contra os sofistas 13.19), não somente havia, em Atenas, jovens sofistas que se dedicavam à alazoneia, mas o faziam excessivamente (pleonazousin).

Em outro discurso contra a educação oferecida pelos sofistas e os inúmeros litígios dela resultantes, Isócrates (Mathieu et Brémond 1942) defendeu um retorno à época em que Atenas era governada pelo Areópago. Segundo ele, sob a tutela do Areópago, os atenienses sempre estiveram livres da alazoneia:

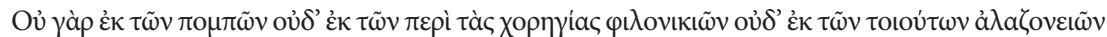

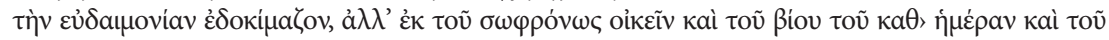

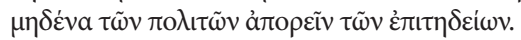

Pois não consideravam a felicidade como oriunda das procissões, das disputas pelo financiamento dos coros, ou de outros tipos de ostentação (alazoneia), mas o portar-se com moderação também em sua vida diária, e o não se eximir de prestar auxílio a nenhum dos cidadãos (Areopagítico 7.53).

O experiente orador insere as competições dramáticas nas manifestações de alazoneia de que desejava libertar a cidade com o retorno da administração areopagítica.

Parece mesmo que o termo alazoneia tinha, em Atenas, um caráter bastante volátil que o fazia aparecer dos dois lados de qualquer disputa verbal. O próprio Isócrates reclama, em Antídose 15.5 e 15.31 (Mathieu et Brémond 
1942), um discurso didático sobre um caso fictício, que seus adversários tendiam a lhe "exagerar" (katalazoneuô) os bens quando o atacavam na corte. Por essa razão, declara (15.75) explicitamente seu temor de que, além disso, seu discurso (to rhêthen) pareça "vanglorioso e exagerado" (alazonikon kai mega). Em sua defesa, afirma (15.195) que, nem mesmo quando era jovem, permitiu a si mesmo qualquer tipo de alazoneia. Finalmente, declara em 15.224 que, diferentemente de outros mestres, cujos alunos os seguem por causa de sua alazoneia, seus discípulos o procuram para adquirir cultura (paideia).

Até um orador do renome de Demóstenes fez questão de se desvencilhar de qualquer nódoa de impostura, afirmando, em seu discurso Sobre a paz, verso 11 (Butcher 1903), um discurso didático sobre um caso fictício, que seus méritos como pensador não estavam predicados na alazoneia. No entanto, Demóstenes costumava se apressar em acusar seus adversários daquilo cuja culpa ele mesmo não admitia. Ainda jovem, em Contra Androtião 22.47 (Butcher 1907), um discurso escrito para outro orador, alveja Androtião, alegando que só será possível descobrir a verdade do processo em questão, se o júri se abstiver de dar ouvidos à alazoneia do acusado. Poucos anos depois, em Contra Mídias 169.2 (Butcher 1907), por precaução, dirige também a Mídias a acusação de alazoneia, mesmo antes de este fazer uso da palavra. De acordo com a Vida de Demóstenes, de Plutarco, o recurso parece lhe ter rendido um de seus primeiros sucessos, pois aceitou retirar a acusação em troca de uma compensação financeira.

Além disso, em sua Defesa de Fórmio 36.41 (Butcher 1907), faz questão de afirmar que Apolodoro se portava como alazôn ao se referir às próprias contribuições para a manutenção de navios de guerra (triêrarchia) e apresentações dramáticas (chorêgia). Trata-se de discurso bastante polêmico em que pesa a suspeita de que Demóstenes, por encomenda de Fórmio, o teria escrito, mas, então, revelado, de antemão, seu teor a Apolodoro a fim de que este pudesse condenar Fórmio à pena de morte. Com esse expediente, Demóstenes desejaria angariar o apoio de Apolodoro para as reformas administrativas que estava propondo. Segundo Plutarco (Demóstenes 15), é possível que Demóstenes tenha, inclusive, escrito tanto o discurso de Fórmio quanto o de Apolodoro, fato que lhe teria brindado uma má reputação em Atenas.

Finalmente, no discurso Apolodoro contra Cálipo 52.20 (Butcher 1903), Demóstenes especificamente procura desmascarar a impostura (alazoneia) de Cálipo, que afirmara ter recebido a soma monetária em disputa como um presente de certo homem chamado Licão. A inverossimilhança da declaração de Cálipo vem principalmente do fato de Licão agir como uma espécie de agiota. Insatisfeito com os poucos juros recebidos de um empréstimo anterior, sabia-se, por exemplo, que Licão chegara a processar um tal Megáclides e seu irmão Trásilo, a quem antes emprestara o mesmo valor. 
Já seria suficientemente danoso que os oradores gregos considerassem a alazoneia como uma falha grave de caráter, mas, além disso, também a consideravam como insuportável defeito de estilo. Em um discurso infelizmente fragmentário (Thalheim 1913), Lísias, por exemplo, faz essa constatação, ao afirmar:

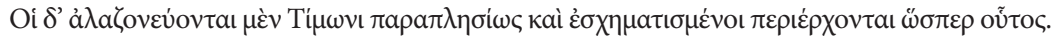

Os que praticam a impostura, assemelhando-se a Timão, também gesticulando, dão rodeios como aquele (Frag. 369).

\section{O ALAZÔN E O AMIGO DO OUTRO}

O orador Ésquines também procurou se livrar da mancha da impostura. Em uma de suas cartas (Martin et Budé 1928), endereçada ao conselho e ao povo de Atenas, afirmou:

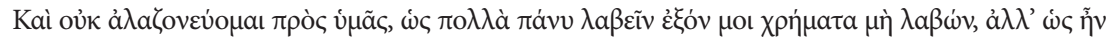

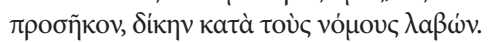

E não me vanglorio junto a vós de, me sendo possível adquirir uma vasta fortuna, não o ter feito, mas, como convinha, de tê-la adquirido por meios legais (Epistola 12.3).

De fato, a impostura era um lugar-comum de presença tão constante nas cortes atenienses que Ésquines, em seu discurso Contra Ctésifon 101 (Martin et Budé 1928), se previne contra ela:

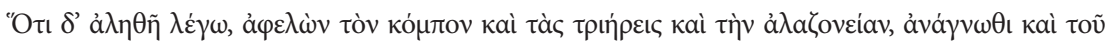

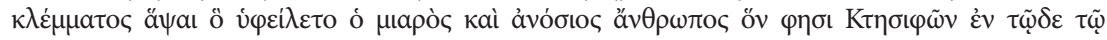

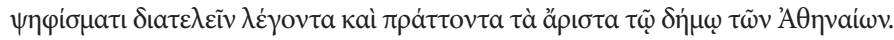

Para provar que estou dizendo a verdade, deixando a grandiloquência, as naus e a impostura, reconhece e atém-te à fraude que empreendeu esse homem abominável e profano de quem Ctésifon argumenta, neste decreto, que está sempre falando e fazendo o melhor para o povo de Atenas.

Trata-se de uma baldada ação movida por Ésquines, em 336 a.C., para impedir a aprovação de uma proposta feita por Ctésifon de que se decretasse uma coroa de ouro para, com ela, recompensar o amigo Demóstenes por valiosos serviços prestados ao Estado. No discurso (218), aparentando indignação, Ésquines se refere mais uma vez à alazoneia de Demóstenes:

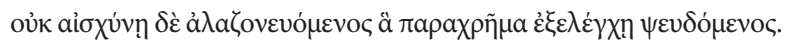

Como não te envergonhas da impostura em que és imediatamente condenado de falsidade! 
E repete (237), então, a Demóstenes, o apelo para que se eliminasse a impostura do decreto em questão:

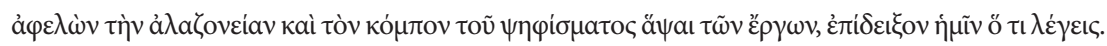

Deixando a impostura e a grandiloquência de teu decreto, atém-te aos fatos, e mostra-nos o que queres dizer.

Depois disso, Ésquines (238) apresenta uma carta do rei da Pérsia na tentativa de patentear o que ele considerava um empenho da parte de Demóstenes para manipular o voto da assembleia. Antes de fazer referência ao conteúdo da epístola, Ésquines a denomina de prova incontestável de impostura:

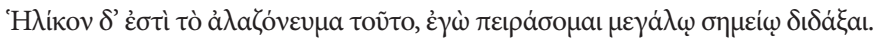

E quão grande é essa impostura, eu mesmo procurarei mostrar com uma prova incontestável.

Finalmente, Ésquines (255-6) revela que sua qualificação das ações de Demóstenes como atos de impostura resulta principalmente de duas características que atribui à conduta daquele orador: seu esforço para se associar com homens abastados e suas alegações de que o Estado ateniense tinha sido grandemente beneficiado por sua militância política:

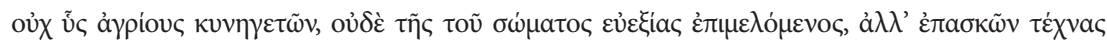

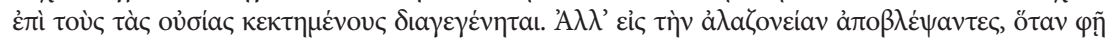

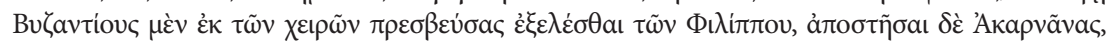

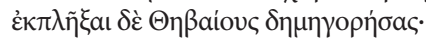

mas ele não esteve engajado na caça de porcos do mato nem em exercícios físicos, mas no cultivo das artes de se associar com aqueles que adquiriram fortunas. Mas percebam sua impostura quando afirma que, como embaixador, conseguiu tirar Bizâncio das mãos de Filipe, causar a revolta da Acarnânia e, apenas com suas palavras, aterrorizar os tebanos.

Se a comparação proposta por Ribbeck (1882) do alazôn com o cavalo se sustenta também na oratória ateniense, é interessante notar que, esporadicamente, se costumava usar ali o verbo epistomizô em referência ao silenciamento de um interlocutor ou outro adversário, como acontece, por exemplo, em A embaixada 2.11o (Martin et Budé 1928), de Ésquines. Como em Aristófanes (Cavaleiros 845), a imposição de cabrestos ou arreios no adversário parece servir para silenciá-lo e controlá-lo (Fraser 1897, 13). De fato, para Ésquines, em Contra Timarco 1.176 (Martin et Budé 1928), é melhor que o orador se atenha a seu tópico com a mesma consistência e disposição com que um cavalo se aplica à corrida do hipódromo. 
Assim, além de colocá-la no âmbito das relações movidas por interesses financeiros, Ésquines faz da alazoneia uma dimensão deturpada do da oratória pública e das relações de amizade. Segundo ele, Ctésifon propõe uma coroa, imerecida, para recompensar seu amigo Demóstenes que, inimigo de Filipe, se associara ao rei da Pérsia, expressão última de alteridade no pensamento grego. Ou seja, o alazôn é sempre o outro. Se, porém, por alguma exceção improvável, não for o outro, será o amigo do outro.

\section{CONCLUSÃO}

No ambiente altamente volátil da corte ateniense, em que a audiência agia de forma ruidosa e intimidadora (República 492 b), sem muitas regras que norteassem o comportamento de seus mais de duzentos juízes, atuando todos ao mesmo tempo, os oradores competiam por credibilidade. Desde o esvaziamento do poder do Areópago e o concomitante fortalecimento das cortes de justiça, essas cortes se tornaram mais politizadas e, em muitos sentidos, passaram a complementar o poder da assembleia (CAREY 1997, $4^{-5}$ ). Diante da enormidade do que se podia ganhar ou perder ali, aqueles que subiam à tribuna voltavam sua energia para difamar seus oponentes com o estigma da alazoneia, denunciando sua suposta impostura, vanglória e contumácia, mas, acima de tudo, procurando demolir sua credibilidade por meio de uma desconfiança generalizada em suas ações e palavras.

A desestabilização dos ideais aristocráticos que permearam a sociedade ateniense nos séculos anteriores contribuiu para o aparecimento de homens loquazes e argutos que adquiriram, no século v e IV, a habilidade de gerar desconfiança nos tribunais, não poupando a ninguém. Como acontecia na comédia antiga, defendiam os próprios interesses sob o pretexto de falar em nome do bem-comum. Usava-se o humor para "alistar o apoio da plateia para um orador, uma vez que, quando riam do oponente, inevitavelmente os espectadores acabavam do lado do orador, de certa forma" (Carey 1990, 49). Assim, o objetivo do orador era vestir o oponente com as roupas do alazôn, minando-lhe a reputação. O expediente mais eficaz para isso parece ter sido empunhar as palavras descritivas da alazoneia com força e rapidez, em estocadas diretas e contínuas. Sua preocupação única parece ter sido simplesmente antecipar o adversário: atacar antes que o outro o fizesse. Nesse processo, percebe-se um forte estranhamento do adversário, que, imerso em uma teia de suspeita, acabava caracterizado como infame, falso, egoísta, indigno, alazôn. Na recorrência até certo ponto cômica dessa estratégia, o alazôn é, sobretudo, o outro ou, pelo menos, o amigo do outro. 
Desta forma, a alazoneia conecta as cortes de justiça atenienses ao espetáculo dos palcos. O agôn que ocorria nas comédias atenienses entre eirôn e alazôn era, em alguns sentidos, um espelho da disputa acirrada que ocorria entre os oradores nos tribunais. O clima de algazarra das cortes e o ambiente irrestrito do teatro grego, um reforçando o outro, contribuíram para o estabelecimento e fixação de um estereótipo de alazoneia predicado especialmente no estranhamento de um oponente visto como outro ou como representante de interesses alheios ao bem-comum:

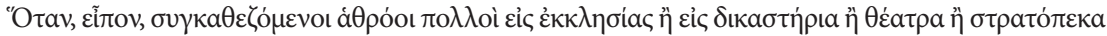

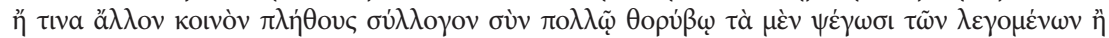

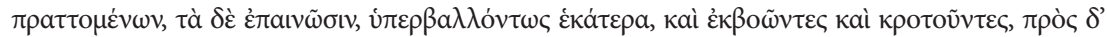

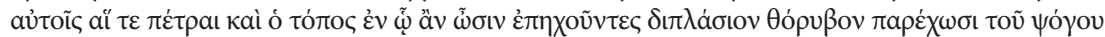

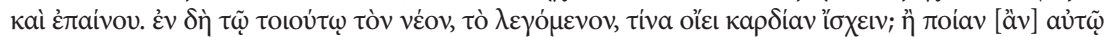

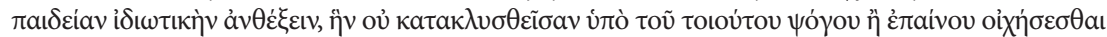

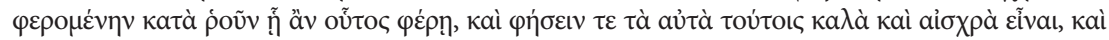

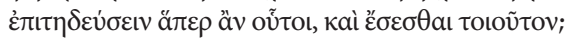

Quando se reúnem em grande número e se sentam todos juntos nas assembleias, nos tribunais, nos teatros, nos acampamentos e outros lugares públicos, e com grande vozerio ora censuram, ora louvam as coisas que se dizem ou fazem, exagerando sempre, aos berros e aplausos, de tal maneira que as pedras em redor e todo o ambiente retumbam, redobrando o estrépito das censuras e louvores. Ao ver-se um moço em tal situação, qual será o seu estado de ânimo? Haverá educação privada que o capacite a resistir à torrente avassaladora da opinião popular, ou se deixará arrastar por ela? Não terá sobre o bem e o mal as mesmas ideias que o público em geral e não se comportará como este, não será exatamente como esse é? (Platão, República 492 b, cf. Burnet 1902).

Comportamentos análogos, passíveis de acontecer no tribunal e no teatro, permitiam liberdades que se tomavam em relação ao alazôn, visto como inimigo do povo e adversário do bem-comum. Resta descobrir se foi o alazôn da comédia que invadiu as tribunas da oratória ou se foi o "alazão" da pnyx que rodeou a acrópole até entrar no teatro de Dioniso. Pelo menos o breve discurso 24 de Lísias, sobre um tema que, em outros aspectos, "não teria quase nenhuma relevância", tem sido amplamente estudado por causa de seu tom cômico (Colla 2011, 112-18), sendo que Carey (1990) chega a afirmar que, nele, o orador usa, de fato, a linguagem da comédia. Além disso, Worman (2008, 115) faz menção que Tucídides (3.36-8), Platão (Górgias 521 e3-522a3), Demóstenes (18.139) e Ésquines (1.126) se referem à plateia dos oradores como possuindo gostos muito semelhantes aos dos espectadores no teatro, gostos estes que se voltavam para estórias originais, anedotas surpreendentes e enunciação dramática. Finalmente, Buis (2008, 249-50) identifica a assembleia (ekklêsia), o teatro e os tribunais como três instâncias cívicas de caráter "perfomativo" em que os cidadãos participa- 
vam ativamente no final do século v a.C., em Atenas, nas quais se criavam espetáculos de natureza agonística. O que parece provável, de qualquer forma, é que o trajeto entre a pnyx e o teatro tenha sido feito inúmeras vezes, senão fisicamente, pelo menos na imaginação do povo, capaz de projetar a imagem de um "alazão" sobre o outro mais depressa do que o trote que conduziria um e outro a seu respectivo lugar.

\section{REFERÊNCIAS}

Bergson, Henri. 1978 [1924]. Le rire: essai sur la signification du comique. 375 ed. Paris: Presses Universitaires de France.

Bethe, E., ed. 1900. Pollucis Onomasticon, v. 1. Leipzig: Teubner.

Bosch, Teresa G. 2000-2001. "Héroes cómicos y actores: una aproximación a Measure for measure". Philologica Canariensia 6/7:205-17.

Boughner, Daniel C. 1943. "The braggart in Italian Renaissance Comedy." Publications of the Modern Language Association of America 58(1):42-83.

Brunoro, Mary-Ann. 1983. The comic contest in Molière and Goldoni. Dissertação de mestrado. The University of British Columbia, Vancouver.

Buis, Emiliano J. 2008. "Diplomáticos y farsantes (Ar. Ach. 61-174): estrategias para una desarticulación cómica de la política exterior ateniense." Estudios Griegos e Indoeuropeos 18:249-66.

Burnet, J., ed. 1902. Platonis opera, v. 4. Oxford: Clarendon.

Butcher, S. H., ed. 1903. Demosthenis orationes, v. 1. Oxford: Clarendon.

Butcher, S. H., ed. 1907. Demosthenis orationes, v. 2. Oxford: Clarendon.

Bywater, I., ed. 1894. Aristotelis ethica Nicomachea. Oxford: Clarendon.

Carey, Christopher. 1997. Trials from Classical Athens. London \& New York: Routledge.

Carvalho da Silva, Joaquim. 2009. Dicionário da língua portuguesa medieval. 2. ed. Londrina: EDUEL.

Casper, Vivian C. 1971. Shaw's plays in the light of theories of comic form: an increasing linear vision. Tese de doutorado. Rice University, Houston.

Cornford, Francis MacDonald. 1961 [1914]. The origin of Attic comedy. Garden City, N.Y.: Anchor.

De Pracontal, Michel. 2004. A impostura científica em dez lições. Tradução de Álvaro Lorencini. São Paulo: Editora da Unesp.

Erbse, H., ed. 1974. Scholia in Iliadem, v. 3. Berlin: De Gruyer.

Fraser, William R. 1897. Metaphors in Aeschines the orator. Tese de doutorado. John Hopkins University, Baltimore.

Frye, Northrop. 1953. "Characterization in Shakespearian comedy." Shakespeare Quaterly 4(3):271-7.

Frye, Northrop. 1957. Anatomy of criticism: four essays. New York: Atheneum.

Hager, Alan. 1991. Dazzling images: the masks of Sir Philip Sidney. Cranbury, NJ: Associated University Presses. 
Hague, Angela. 1984. Iris Murdoch's comic vision. Cranbury, NJ: Associated University Presses.

Hoffmann, Rachel. 2008. O bestiário humano: a ironia em A república dos corvos de José Cardoso Pires. Dissertação de metrado. Universidade Estadual Paulista, São José do Rio Preto.

Holman, C. Hugh; Harmon, William. 1986. A handbook to literature. 5. ed. New York: Macmillan.

Hutcheon, L. 2000. Teoria e política da ironia. Tradução de Júlio Jeha. Belo Horizonte: UFMG.

Martin, V.; Budé, G., ed. 1928. Eschine: discours, v. 2. Paris: Les Belles Lettres.

Mathieu, G; Brémond, É., ed. 1929. Isocrate: discours, v. 1. Paris: Les Belles Lettres.

Mathieu, G; Brémond, É., ed. 1942. Isocrate: discours, v. 3. Paris: Les Belles Lettres.

Renan, Yael. 1983. "'Angelfaces clustered like bright lice': comic elements in modern writing." Comparative Literature 35(3):247-61.

Ribbeck, Otto. 1882. Alazon ein Beitrag zug Antiken Ethologie. Leipzig: G. Teubner.

Smith, O. L., ed. 1976. Scholia Graeca in Aeschylum quae exstant omnia, vv. 1-2. Leipzig: Teubner.

Speckhard, Robert R. 1958. Shaw and Aristophanes: a study of the eirôn, agôn, alazôn, doctor/cook and sacred marriage in Shavian comedy. Tese de doutorado. Universidade de Michigan, Ann Arbor.

Storey, Ian C. 1998. "Poets, politicians, and perverts: personal humour in Aristophanes." Classics Ireland 5:85-134.

Suter, Ann. 1993. "Paris and Dionysos: iambos in the Iliad." Arethusa 26(1):1-18.

Thalheim, T., ed. 1913. Lysiae orationes. 2. ed. Leipzig: Teubner.

Vallandro, Leonel, trad. [s.d.] Platão, Diálogos: A República. Rio de Janeiro: Globo.

Willcock, M. M., ed. 1978. Homer - Iliad: books I-XII. London: Bristol Classical Press.

Title. The alazôn, the other, and the other's friend: theater of distrust in greek podium Abstract. The alazôn appears frequently as a "blocking character" (otherwise known as "killjoys") in Aristophanes' comedies. He uses his greater social status, stiffness, boasting and deception in order to prevent the realization of a comic utopia. The term is also used in ancient Greece for the horse race (Pollux, Onomasticon 1195) due to the impressive way stallions display their horsehair. Besides comedy, Greek rhetoric also makes abundant use of the term, applied usually to an opponent. Since a speaker's performance is compared to the disposition of the horse at the racetrack (Aeschines, Against Timarchus 1176) and since the hubbub of the Athenian court is comparable to the theater (Plato, Republic 492b), it is suggested that the alazoneia topos serves to stigmatize a character (in the theater) or a speaker (in the podium) as opportunistic, an enemy of the common good, and a representative of interests which are foreign to the polis. In this process, it is possible that its use in comedy and oratory mutually reinforce that stigma, promoting a widespread distrust of the speaker/alazôn and of the people associated with him.

Keywords. Alazôn; Old Comedy; Greek orators; Greek rhetoric. 